\title{
MAKNA PENDERITAAN ORANG SALEH MENURUT KITAB AYUB
}

\section{Dora Hutasoit}

\section{PENDAHULUAN}

Hukum providensia Tuhan, seringkali diinterpresentasikan terlalu dangkal: Orang saleh diberkati, orang fasik dihukum. Akibatnya pada hakikatnya kata saleh dan menderita tidak dapat bertemu. Kendati demikian, justru kitab Ayub memaparkan bahwa kedua hal itu bertemu di dalam pengalaman hidup Ayub.

\section{ARTI KESALEHAN AYUB} berikut ini.

Untuk mengerti lebih dalam, maka perlu dibahas beberapa aspek

\section{A. Terminologi Kesalehan Ayub}

TB: pasal 1:1 : “... bernama Ayub; orang itu saleh (tam) dan jujur (Yashar); ia takut akan Allah (Yere Elohim) dan menjauhi kejahatan (Sar mera)."

Kata saleh (tam), menurut Gesenius : whole, upright, always in a moral sense $(1: 1 ; 8: 20,21,22)^{1}$ William Wilson, to complete, to perfect, to be finished. ${ }^{2}$ RSV: blameless, LXX : $\varsigma 8024<\cong \mathrm{H}$

Bahasa Ibrani tam, berarti: kejujuran, ketulusan hati, seperti yang diungkapkan Kejadian 20:5, betam lebabi (TB : ... kulakukan dengan hati yang tulus dan ...). Barnes mengungkapkan, Such is properly the meaning of the word as derived from "tamim", to complete, to make full, perfect or entire, or to finish. ${ }^{3}$ Perfect di sini, bukan berarti sempurna tanpa dosa, karena hanya Allah yang sempurna, sebagaimana yang diungkapkan dalam Roma 3:23; Pengkhotbah 7:20: Karena semua orang telah berbuat dosa dan telah kehilangan kemuliaan Allah, ... Sesungguhnya, di bumi tidak ada

\footnotetext{
Willem Gesenius, Hebrew And Chaldee Lexicon To The Old Testament Scriptures (Grand Rapids : Baker Book House, 1981), 865.

William Wilson, Wilson's Old Testament Word Studies (MC Lean : Mac Donald Publishing Co., n.d.), 480.

Albert Barnes, Notes On The Old Testament Explanatory And Practical, Job. Vol.I (Grand Rapids : Baker Book House, 1971), 92.
} 
orang yang saleh: ... dan tak pernah berbuat dosa.

Perfect di sini mencakup : ketulusan hati, kejujuran dalam segala segi kehidupan. Istilah perfect (tam), sama seperti yang diungkapkan bagi Nuh (Kej 6:9: Nuh adalah orang yang benar dan tidak bercela ...) Juga dalam Matius 5:48: Karena itu haruslah kamu sempurna.

Dengan demikian istilah saleh (tam) berarti: tulus dan jujur, tidak ada tipu kejahatan atau kelicikan, penuh kesungguhan dalam ibadah, tanpa ada niat untuk melakukan yang jahat, sebagaimana dalam pengakuan Ayub $(9: 20 ; 42: 5,6)$ :

Sekalipun aku benar, mulutku sendiri akan menyatakan aku tidak benar; sekalipun aku tidak bersalah, ya akan menyatakan aku bersalah. Hanya dari kata orang saja aku mendengar tentang Engkau, tetapi sekarang mataku sendiri memandang Engkau. Oleh sebab itu aku mencabut perkataanku dan dengan menyesal aku duduk dalam debu dan abu.

Maka berdasarkan arti kata tam, Ayub adalah seorang yang saleh di hadapan Allah, dalam arti: hatinya baik terhadap Allah maupun dalam segala relasi kehidupan sosial; juga kematangan dalam bidang moral, watak yang seimbang dan berkepribadian mantap (always in a moral sense) kepada Allah dan kehidupan sosial. ${ }^{4}$

Kata jujur (yasar), menurut Wilson: straight, rigt upright, righteous, just (1Sam 29:6). ${ }^{5}$ Delitzsch menjelaskan: In thought and action without deviation comformed to that which is right. ${ }^{6} \mathrm{~TB}$ : Jujur; RSV: up right.

Jadi Yasar, mengandung pengertian: Lurus atau to be straight, benar (dari segi moral dan yang berkaitan dengan sifat Allah) atau up right (hart).

Dengan demikian Ayub hidup jujur, tidak ada pikiran untuk menyimpang atau melawan Allah. Segala yang dibuatnya, diucapkannya, dipikirkannya, terarah kepada hal kebaikan. Dia Setia dalam janji atau ucapannya.

Kata takut akan Allah (Yere Elohim). Menurut R.L. Harris: Yare (kata dasarnya) berarti: fear, to be afraid, revere (menghormati, menjunjung). Jadi Yere Elohim, diterjemahkan: fearing God istilah yare, berkaitan dengan teks kitab Ayub adalah:

- righteous behaviour at piety

- formal religious worship.

4 E.S.P. Heavenor, Ayub, dalam D. Gutrie (ed.), Tafsiran Alkitab Masa Kini. II (Jakarta : BPK. Gunung Mulia, 1980), 71.

$5 \quad$ Wilson, Wilson's Old Testament..., 463.

6 F. Delitzch, Job dalam C.F. Keil, Commentary On The Old Testament. Vol. IV Grand Rapids: Wm. B. Eerdman Publishing Co, 1978), 48.

7 R. Laird Harris, The Theological Wordbook of The Old Testament. Vol. I (Chicago : Moody Press, 1980) 399-400. 
Jadi, fearing God atau takut akan Allah berarti:

- Takut atau berjaga-jaga, agar jangan sampai ia berjalan tidak pada jalan

- Allah

- Sikap salah dalam menghadapi firman Tuhan

- Ketakutan yang merupakan lawan dari kejahatan (bnd. Pkh. 8:13)

Menjauhi kejahatan (sar mera). Menurut Gesenius, sar dari kata sur, yang berarti : to turn aside, to go away, to depart. ${ }^{8}$ Wilson: to go off, to trun aside or away. ${ }^{9} \mathrm{RSV}$ : turning away from evil.

Jadi sar mera mengandung pengertian: menghormati dan menjunjung Tuhan (takut akan Tuhan). Tindakannya selalu berusaha melakukan yang terbaik, sesuai kehendak Tuhan dan menjauhi kejahatan.

Pasal 1:1, melaporkan tentang kesalehan Ayub. Pasal 1:8, kesalehan Ayub juga diakui Tuhan, bahkan dikatakan bahwa tidak ada seorangpun di bumi seperti Ayub dalam hal kesalehan dan kebaikannya. Berarti kesalehan dan kebaikan Ayub sangat dominan, dalam hubungan dengan Tuhan maupun dengan masyarakat.

B. Wujud Kesalehan Ayub.

\section{Wujud Kesalehan Ayub Dalam Hubungan Dengan Tuhan}

Pasal 1:8; 2:3, mengungkapkan bahwa Allah sangat memperhatikan, melindungi, dan membela Ayub, hamba-Nya yang saleh.

TB pasal 29:4, seperti ketika aku mengalami masa remajaku (bimey kharepi), ketika Allah bergaul karib (besod) dengan aku di dalam kemahku.

BIS, Itulah hari-hari kejayaanku, ketika keakraban Allah menaungi rumahku; RSV, As I was in my autum days, when the friendship of God was upon my tent. NIV, Oh, for the days when I was in my prime, when God's intimate friendship blessed my house.

Menurut Brown, kharepi (masa remajaku), mengandung arti as my implying naturity. ${ }^{10}$ Barnes mengatakan, The whole passage shows what it does not mean youth, for he goes on to describe the honour and respect shown to him when in nature life. ${ }^{11}$

Dari Septuaginta, $\Theta \vartheta \gamma \quad \ldots \Lambda 0<\quad \Xi B 4 \exists \Delta 42 T<{ }^{T M} * \cong \Lambda H \ldots$ (When I

\begin{tabular}{cc}
\hline 8 & Gesenius, Hebrew And Chaldee..., 582. \\
9 & Wilson, Wilson's Old Testament..., 458. \\
10 & Francis Brown, The New Brown - Driver - Briggs - Hebrew And English \\
Lexicon (Lafayette : Associaate Publishers And Authors Inc., 1978), 358. \\
Barnes, Notes On ... II, 75.
\end{tabular}


made heavy or laded my ways ...). An expression referring to autum as being laden with fruit. ${ }^{12}$ Juga Tirren menulis,

He lived then in the days of 'fruit gathering' a season which for the ancient mind did not suggest the late maturity that ushers in the winter old age, but rather the time when nature yields her increase and the early rains the energy of truimphant adulthood. ${ }^{13}$

Jadi yang dimaksud bimey kharepi (masa remajaku), yaitu pada masa jaya yang efektif.

Biasanya, pada masa jaya-jayanya, orang justru lebih tertarik pada glamour dunia yang menggiurkan. Namun bagi Ayub, tidak ada yang lebih indah dan menarik, yang dapat disejajarkan dengan hidup bergaul akrab dengan Tuhan (juga dialami Daud; bnd. Mzm 27:4).

Pengalaman akrab dengan Tuhan, justru merupakan pengalaman rohani yang sangat indah dan dalam, yang tidak mungkin tergantikan oleh apapun juga. Kenikmatan tersebut hanya dapat di mengerti dan dialami dalam wujud hubungan akrab dengan Tuhan, sebagai orang saleh. Barnes menjelaskan demikian sebagai berikut.

The word rendered secret (sod), means a couch or cushion on which one reclines, and then a divan, or circle of friends sitting to gether in consultation. The idea here probably is, that God came into his tent or dwelling as a friend and that job was, as it were, admitted to the secrecy of his friendship and to an acquaintance with his plans. ${ }^{14}$

Di dalam Vulgata tertulis, When God was secretly in my tabernacle. Sedangkan di dalam LXX tertulis, When God watched over - $f B 4 \Phi_{l} \cong B 0<$ $f B \cong \wp \infty 4 \cong-$ my house.

Dengan demikian dapat disimpulkan bahwa hubungan Ayub dengan Allah begitu intim, merupakan sahabat karib, dimana Allah dapat menyatakan rahasia-Nya, kehendak-Nya, dan rencana-Nya.

Dari beberapa ungkapan Ayub berikut ini, dapat terlihat keteguhan imannya, kedalaman pengertian rohaninya, yang hanya dapat diucapkan oleh orang yang kehidupan rohaninya sungguh saleh dan akrab dengan Tuhan, antara lain:

- ... Tuhan yang memberi, Tuhan yang mengambil, terpujilah nama Tuhan! (1:21)

- ... Apakah kita mau menerima yang baik dari Allah, tetapi tidak mau menerima yang buruk (2:10)

\footnotetext{
12 Barnes, Notes On The..., II, 75.

13 Samuel Tirren, "Job" dalam George Arthur Buttrick (ed.), The Interpreter's Bible, Vol. III (Nashville : Abingdon, 1978), 1108.

14 Barnes, Ibid., 76.
} 
- Tetapi aku tahu : Penebusku hidup dan akhirnya Ia akan bangkit di atas debu (19:25, keyakinan yang mendasar). Juga pengertian Ayub mengenai dosa, sungguh sangat dalam (27-31).

Dari semua contoh yang dikemukakan, hubungan erat dengan Tuhan, kesungguhan menjaga kesalehan hidup, ketaatan kepada kehendak Tuhan, keteguhan rohaninya di dalam segala penderitaan, semuanya menunjukkan kesalehan Ayub, sebagaimana yang dinyatakan Allah mengenai hamba-Nya Ayub (1:8).

\section{Wujud Kesalehan Ayub Dalam Hubungan Dengan Keluarga}

Pasal 1:4-5, mengungkapkan kesalehan Ayub di dalam keluarga dari beberapa segi.

\section{a. Dari Segi Mendidik Kesatuhan Keluarga}

Sangat menarik bahwa Ayub menerapkan sistem demokrasi terpimpin dalam keluarganya. Dia merestui anak-anaknya mengadakan pesta bergilir, namun dia juga mengarahkan dan mendoakan mereka satu persatu.

\section{b. Dari Segi Figur Seorang Kepala Rumah Tangga Yang Saleh}

Rupanya kebiasaan yang baik, yaitu persekutuan antar keluarga dalam jamuan minum secara bergantian, dibina dan direstui oleh bapak Ayub, melalui pengarahan rohani dan doa (1:5). Kerukunan dan keharmonisan dalam keluarga besar Ayub merupakan satu keluarga kristen teladan, dalam kesalehan, kedamaian, keakraban, kerukunan dalam kesukaran. Ini sungguh merupakan keluarga keberkatan yang sangat ideal dan didambakan setiap orang.

Di balik segala kesuksesan itu, ada rahasia yang sangat mendasar dan prinsipiil, yang dilakukan Ayub, yaitu setiap kali hari-hari pesta berlalu, Ayub mengumpulkan semua anaknya dan menguduskan mereka (waykadesem; 1:5). Istilah kadas, berarti: menguduskan, membersihkan, membasuh.

Hal itu merupakan tindakan seorang iman, yang menguduskan seseorang yang dikhawatirkan berbuat dosa dan biasanya diikuti oleh pengertian bahwa hal itu menghasilkan pengampunan dosanya. ${ }^{15}$

Juga dikatakan sebanyak jumlah mereka (mispar kulam), artinya

$15 \quad$ Barnes, Notes On The..., II, 97. 
according to their number, berdasarkan kemungkinan anaknya telah berbuat dosa. Pada waktu itu, di zaman patriarkh, kebiasaan membakar korban:

- Dilaksanakaan oleh seorang bapak sebagai kepala keluarga (Kej $12: 7-8,13: 18)$

Biasanya dilakukan pada pagi-pagi sekali (Kej 22:3; Kel 32:6). Juga Tuhan Yesus berdoa pagi-pagi sekali (Mrk 1:35) ${ }^{16}$

Perlu diperhatikan, bahwa Ayub melakukannya secara berkesinambungan, sesuai prinsip rohani, seperti dikatakan Mathew Henry, The acts of repentance and faith must be often renewed, because we often repeat our transgression. He that secves God uprightly will serves Him continually. ${ }^{17}$ Ini merupakan respek kesalehan Ayub yang senantiasa berjaga-jaga untuk hidup benar di hadapan Tuhan.

c. Wujud Kesalehan Ayub Dalam Hubungan Dengan Masyarakat

1) Segi Perkataan

Kata-kata: pengajaran, pengarahan, nasehat, penghiburan, menguatkan $(4: 3,4)$, Aeschylus mengatakan, words are the physicians of $a$ mind diseased. ${ }^{18}$

Dalam memberi pengarahan, bagaimana menanggung dan mengatasi penderitaan; nasehat untuk menguatkan dan menghibur yang lemah, kecewa dan putus asa; membangun yang jatuh dalam dosa, kesusahan, musibah atau pencobaan; mengokohkan dan menunjang lutut yang lemah, yang tidak sanggup lagi berdiri dengan kekuatan sendiri; dalam iman, percaya diri, dan lainnya.

2) Segi Tindakan Praktis (29:12-25)

Selain keharmonisan dalam keluarga, Ayub juga merupakan teladan dalam kehidupan sosial masyarakat, seperti dalam 29:14; Aku berpakaian kebenaran dan keadilan menutupi aku seperti jubah dan serban.

Kesadarannya berbuat baik terhadap masyarakat seimbang dengan hidup persekutuan yang benar dengan Allah. Ia bukan hanya menjadi mata bagi orang buta, kaki bagi orang lumpuh, bapak bagi orang miskin, tetapi juga menyelidiki perkara orang yang tidak ia kenal (29:15-16). Maksudnya sebagai hakim pembela perkara orang asing dan menyelidikinya dengan

\footnotetext{
16 Jamieson, Commentary Critical ..., 310.

17 Mathew Henry, Commentary On The Whole Bible (Grand Rapids: Zondervan Publshing House, 1960), 515.

18 Tirren, Job, 934.
} 
seksama. ${ }^{19}$ Rasa sosialnya yang tinggi mendorong dia membela orang tertindas (29:17).

\section{PENDERITAAN AYUB}

A. Penderitaan Jasmani

Menurut pasal 1 dan 2, ada dua tahap penderitaan jasmani yang dilancarkan Iblis kepada ayub dan seizin Allah.

\section{Penderitaan Jasmani Tahap Pertama}

Firman Tuhan kepada Iblis: Nah, segala yang dipunyainya ada dalam kuasamu; hanya janganlah engkau mengulurkan tanganmu terhadap dirinya (1:12).

Pada tahap pertaama ini, Iblis diberi kuasa atas segala milik Ayub, kecuali menyakiti atau melukai tubuhnya. Sesuai sifatnya, Iblis segera melancarkan serangan bertubi-tubi kepada Ayub, dengan perhitungan yang sangat jitu tanpa belas kasihan, namun hanya sebatas yang diizinkan Tuhan.

Mula-mula lembu-sapi, keledai dan penjaganya dirampas dan dipukul oleh orang-orang Syeba dengan ganas $(1: 14,15)$. Disusul kambingdomba dan penjanganya, disambar api dari langit (1:16). Mengenai api dari langit, Elmer B. Smick menjelaskan demikian:

... the fire of God ..., may be either lightning (Pope, 14) or brimstone (Delitzcch, 1:6). The terminology "of God" as part of a cliche does not mean God is considered the immediate source in this contest. It is simply phenomenological language because it came from heaven. ${ }^{20}$

Disusul, unta-unta dan penjaganya, dirampas dan dipukul oleh orang Kasdim. Kemudian ditutup dengan yang paling berarti yaitu: anak-anak lelaki dan perempuan mati dilanda angin ribut dari seberang padang gurun $(1: 18,19)$.

Semua harta Ayub sampai yang paling berarti yaitu anak-anaknya, lenyap dalam sekejap. Suatu berita duka yang sangat dahsyat dan kejam, yang sudah diperhitungkan masak-masak oleh Iblis. Barnes menulis mengenai hal ini sebagai berikut.

All this indicates the rapidity of the movement. of Satan, and his

19 Barnes, Notes On The ..., Vol. II, 79.

$20 \quad$ Elmer B. Smick, “Job," dalam Frank E. Gaebelein (ed), The expositor's Bible Commentary, Vol. IV (Grand Rapids: Zondervan Publshing House, 1988), 883. 
disire to overwhelm Job with the suddenness and greatness of his calamities. The object seems to have been to give him no time to recover from the shock of one form of trial before another came upon him. If an interval has been given him he might have revield his strength to bear his trial; but afflictions are much more difficult to be borne when they come in rapid succession. ${ }^{21}$

Siapapun orangnya, saleh maupun fasik, bila ditimpa musibah serupa ini, pastilah mendatangkan duka cita dan penderitaan yang sangat dahsyat.

Untuk menghadapi masalah seperti ini, Tirren mengungkapkan demikian: What the problem needs is a change of venus, wich is precisely what the Bible gives it: not why is evil permilted, but how is evil overcome $?^{22}$ Ucapan dan sikap Ayub senada dengan kematangan rohaninya sebagai hamba Tuhan yang saleh $(1: 20,21)$.

\section{Penderitaan Jasmani Tahap Kedua}

Gagal dengan serangan pertama, Iblis mulai dengan serangan kedua; Tetapi ulurkanlah tangan-Mu dan jamahlah tulang dan dagingnya, ia pasti mengutuk Engkau di hadapan-Mu. Maka firman Tuhan kepada Iblis: Nah, ia dalam kuasamu; hanya sayangkan nyawanya $(3: 5,6)$.

Pada tahap kedua ini jangkauan kekuasaan Iblis diperluas sampai kepada tubuhnya (tulang dan daging). T.B ... Lalu ditimpanya Ayub dengan barah yang busuk (shekhin ray) dari telapak kakinya sampai kebatu kepadanya. RSV ... Job with loathsome sores.

Shekhin ray (bad burning ulcera), ini tidak sama dengan lepra yang diungkapkan (Im 13:9-11; Ul 24:8; 2Raj 5:3); tetapi lebih buruk lagi (Im 13:18-23). Rupanya serupa dengan tulah di Mesir (Kel 9:9-11), yaitu puru atau bisul jahat yang diderita raja Hizkia (2Raj 20:7 dan Ul 28:35), yang menjijikan, yang timbul di seluruh permukaan kulit, seperti yang dialami Ayub, dari kaki sampai keatas kepala. ${ }^{23}$

Penyakit itu sangat mengerikan dan Ayub sangat menderita karenanya. Suatu penderitaan yang melucuti seluruh kehormatan Ayub dan merampas semua relasi dalam keluarga maupun masyarakat. Ini merupakan penderitaan jasmani yang sangat kuat, namun ada penderitaan lain yang lebih berat lagi yang Ayub alami.

\footnotetext{
$21 \quad$ Barnes, Notes On The ..., Vol. I, 106.

22 Tirren, $J o b, 915$.

23 Barnes, Ibid., 122.
} 
B. Penderitaan Rohani

Ada beberapa hal yang membawa Ayub masuk kedalam penderitaan rohani.

1. Pengaruh Kunjungan dan Nasehat Tiga Sahabat Ayub

Semula maksud kunjungan tiga sahabatnya mau menyatakan keprihatinan dan menghibur (2:10-13) Namun pasal 3 menceritakan bahwa Ayub masuk ke dalam pergumulan penderitaan yang lebih dalam, sampai menggoyahkan kestabilan rohaninya. Sebelumnya, baru saja Ayub memproklamirkan imannya yang tidak dapat digoyahkan oleh apapun $(1: 21,22 ; 2: 10)$.

Sikap ketiga sahabatnya bukannya mengekspresikan keprihatinan, namun cenderung menghakimi Ayub sebagai seorang terhukum yang diganjar setimpal dengan dosanya. Kesimpulan ketiga sahabat Ayub didasarkan atas hikmat manusia yang sempit terhadap hukum providensia yaitu orang saleh diberkati, orang fasik menderita. Interpretasi yang dangkal ini bagaikan rentetan peluru yang menyakitkan, bahkan menggoyahkan iman Ayub, yang merupakan dasar kekuatannya. Inilah siasat jitu Iblis yang masih sangat relevan sampai pada zaman modren ini, yaitu menghancurkan iman percaya orang saleh.

\section{Peran Iblis Dalam Penderitaan Ayub}

Sesuai arti dan sifat Iblis (satan), tidak pernah berhenti menentang Allah, melalui aneka strategi liciknya. Obyek sasarannya adalah manusia dari segala zaman dan di sini adalah Ayub.

Sesuai 1 Petrus 5:8, Iblis selalu aktif dan gigih di dalam segala kesempatan dan kesempitan menentang Allah dan orang percaya. Hal ini jelas diungkapkan dalam $1: 7 ; 2: 22$. TB ...dari perjalanan mengelilingi (shot) dan menjelajah (mehithallek) bumi. Dari teks Ibrani shot dan mehithallek, mengandung arti : to go eagerly to and fro. Hitpael : run to and fro. ${ }^{24}$ Ayat ini menjelaskan bahwa Iblis sangat giat dan gigih mengadakan survey di segala pelosok dunia, mencari celah untuk memperdaya anak-anak Tuhan atau orang saleh.

Di sini peran Iblis sangat besar dalam penderitaan Ayub (orang saleh), yaitu untuk memisahkannya dari kasih Anugerah Allah, merongrong kesalehannya dan menghancurkan kehidupannya agar menjadi musuh Allah. Dari aksi yang dilancarkan Iblis, ada dua segi yang disoroti, yaitu:

$24 \quad$ Barnes, Notes On The ..., Vol. I, 1002. 
a. Percobaan Iblis Untuk Merenggut Iman Ayub

Secara jasmani: mengambil segala miliknya dan menghancurkan kesehatannya. Dari dua strategi percobaan Iblis ini, malah imannya semakin kuat $(1: 21-22 ; 2: 10)$.

b. Ujian Allah

Serangan Iblis ternyata seizin Allah, yang menggunakannya sebagai ujian kesalehan Ayub. Di sini nampak kemutlakan kuasa Allah, yang membatasai ruang gerak kekuasaan Iblis terhadap orang saleh yang berada dipihak Allah:

- Ujian Allah untuk mengungkap maksud mulia Allah bagi Ayub

- Ujian Allah untuk mengungkap kesetiaan-Nya menyertai manusia

Iblis memperhatikan untuk menyerang, dan menghancurkan, namun Tuhan memperhatikan untuk melindungi dan menyelamatkan.

\section{MAKNA PENDERITAAN AYUB}

A. Makna Penderitaan Ayub Sebelum Kunjungan Tiga Sahabatnya

Ada dua hal yang dapat dipakai sebagai barometer untuk makna penderitaan Ayub, yaitu: sikapnya dan perbuatannya.

- Maka berdirilah Ayub, lalu mengoyak jubahnya dan mencukur kepalanya, kemudian sujudlah ia dan menyembah, katanya, dengan telanjang aku keluar dari kandungan ibuku, Tuhan yang memberi, Tuhan yang mengambil terpujilah nama Tuhan! (1:20-21)

- Sikap dan perkataan kepada istrinya (2:10)

Berikut beberapa sikap Ayub yang mewarnai pandangannya terhadap penderitaan yang menimpanya.

1. Maka berdirilah Ayub ... sikap ini mengandung pengertian: the begining to do anything (bnd. 2Sam. 13:31) ${ }^{25}$

2. Ia mengoyakkan jubahnya dan mencukur rambut kepalanya. Sikap ini menunjukkan bahwa dia sangat berdukacita (bnd. 19:37: 34) ${ }^{26}$

25 Jamieson, Commentary Critical ..., 311.
26 Ibid. 
3. Ia sujud dan menyembah. Hal ini merupakan sikap merendahkan diri dalam keadaan tak berdaya dan memberi hormat serta berbakti. Barnes mengungkapkan sebagai berikut.

Job seems to have done this partly as an axpression of grief, and partly as an act of devotion, solemly bowing before God in the time of his great trial. And worshipped. Worshipped God, he resigned himself to his will. A pious man has nowhere else to go in trial; and God who has afflicted him. ${ }^{27}$

4. Sikap tegas Ayub terhadap kelemahan istrinya, menunjukkan kekuatan rohaninya. Selain sikapnya, juga perkataan yang keluar dari mulutnya, memberi arah pandangan Ayub terhadap penderitaan yang menimpanya.

5. Dengan telanjang ..., berarti tidak mempunyai apa-apa (bnd. 1Tim. $6: 7)$

6. ... dari kandungan ibuku ... . Menurut Jamieson kalimat ini sebagai ungkapan bahasa puitis yang maksudnya : the earth, the universal mother (bnd. Mzm 139:13, 15; Kej 3:19); Kembali kepada tanah dan debu. ${ }^{28}$ Juga Barnes mengatakan, Job felt that he was stripped of all, and that he must leave the world as destitude as he entered it. ${ }^{29}$

7. Tuhan yang memberi, Tuhan yang mengambil... suatu pernyataan Ayub yang jujur, bahwa semuanya dari Tuhan. Juga diungkapkanya dalam 2:10: Bahwa Tuhan memberi (menerima yang baik...) dan mengambil. Semua itu adalah hak Tuhan. Ia tidak berhak memanipulasi hak Tuhan untuk mengukur kasih setia Tuhan.

Akhirnya perkataan Ayub terhadap penderitaannya, ditutup dengan memuji Tuhan baik pasal 1:21, maupun pasal 2:10 (Tuhan tidak salah). Hal ini sangat berlawanan dengan ungkapan Iblis, sebagai bapak pendusta dan penuduh, bahwa kalau Tuhan mengambil maka Ayub akan mengutuk Tuhan (2:6).

Jadi makna penderitaan Ayub, berupa apapun, tidak berkuasa menggoyahkan iman percayanya kepada Tuhan. Bahkan melalui penderitaan, kekuatan dan pengertian rohaninya semakin teruji dan murni.

\footnotetext{
$27 \quad$ Barnes, Notes On The..., Vol. I, 110.

28 Jamieson, Commentary Critical ..., 311.

29 Barnes, Ibid.
} 
B. Makna Penderitaan Ayub, Setelah Kunjungan Tiga Sahabatnya

Dengan konsep hikmat manusia yang dangkal dan sempit, dapat berdampak fatal (lebih menderita) bagi orang yang dilayani, baik segi ragawi maupun rohani; bahkan sampai menggoyahkan imannya, yang menjadi dasar kekuatan Ayub.

\section{Makna Penderitaan Ayub Setelah Kunjungan Allah}

Melalui kunjungan dan penyataan Allah kepada Ayub, membawa dia berhadapan langsung dengan kedaulatan dan hikmat Allah yang Agung, Intervensi Allah terhadap Ayub.

1. Sang Pencipta (ps. 38)

Membuka mata Ayub untuk melihat Siapa saya dan siapa engkau.

2. Allah Yang Mahakuasa (ps. 38-41)

Tidak ada satupun ciptaan-Nya, termasuk Ayub, yang dapat menandingi kekuasaan-Nya. Di sini Ayub berhadapan dengan kemutlakan kedaulatan kuasa Allah dan kesempurnaan-Nya untuk mengatur dan memperhatikan ciptaan-Nya, terlebih kehidupan Ayub.

3. Allah Yang Memelihara dengan Kasih Setia

Kehadiran Allah dengan kasih setia-Nya yang memelihara, menghembuskan angin segar, sehingga Ayub merasa malu dan merendahkan diri di hadapan keagungan-Nya (39:37-38). Berhadapan dengan Allah yang sedemikian, tidak ada lagi kata-kata yang dapat ia ucapkan sebagai pembenaran diri.

4. Allah Hakim Yang Agung, Adil, dan Benar

Berhadapan dengan Allah sebagai Hakim Agung Yang Benar dan Adil, Ayub tidak mampu lagi adu argumentasi sebagai pembenaran diri (39:34-38; 42:1-6).

Ayub benar-benar merasa ditelanjangi dan dipermalukan. Pertemuan pribadi dengan Allah, telah menggugah hati dan pikiran Ayub, merubah cara dia berpikir dan bersikap, yang membawa Ayub sampai kepada pertobatan total, serta masuk ke dalam persekutuan indah dan mesra dengan Allah.

Proses penderitaan Ayub dengan seizin Allah telah membuka matanya untuk melihat, mencerahkan pikiranya untuk mengerti dan 
menerangi hatinya untuk menemukan :

D. Makna Penderitaan Orang Saleh

1. Pertobatan Ayub yang Dalam, Penuh Kesungguhan

Hanya dari kata orang saja aku mendengar tentang Engkau, tetapi sekarang mataku sendiri memandang Engkau (42:5).

2. Pembenaran Allah

Hidup kerohaniannya diperkaya dan dikuatkan oleh perbuatan Allah. Perkataan Ayub menyebabkan dia dibenarkan dan makin dekat dengan Allah, yang mengatakan, Hambaku Ayub, yang doanya kudengar dan kuterima (42:8).

3. Pemulihan Allah

Alangkah mulia dan sempurnannya maksud dan rencana Allah bagi Ayub, orang saleh, melalui penyataan-Nya. Hubungan Ayub, orang saleh, dengan Tuhannya menjadi semakin dekat dan intim. Melalui pembenaran Allah, Ayub dilayakkan menjadi imam (perantara) bagi sahabat-sahabatnya. Melalui pemulihan Allah, Ayub dimampukan untuk mengampuni sahabat-sahabatnya yang telah mengecewakan dia. Prinsip rohani menjadi bagian dalam hidupnya, Ampunilah maka kamu diampuni, berilah maka kamu akan diberi (Luk 6:37c-38a).

Kesempurnaan pemulihan Allah, bukan saja sebatas perkara rohani, namun juga menjangkau perkara jasmani. Semua ini membuktikan bahwa Tuhan adalah Allah Yang Mahamurah. Dia memelihara Ayub orang saleh dengan sempurna.

\section{KEPUSTAKAAN}

Barnes, Albert

1971 Notes On The Old Testament Explanatory And Practical Job. Vol.I. Grand Rapids : Baker Book House.

Brown, Francis

1978 The New Brown - Driver - Briggs - Hebrew And English Lexicon. Lafayette: Associaate Publishers And Authors Inc. 
Buttrick, George Arthur (ed.)

1978 The Interpreter's Bible. Vol. III. Nashville : Abingdon.

Gesenius, Willem

1981 Hebrew And Chaldee Lexicon To The Old Testament Scriptures. Grand Rapids: Baker Book House.

Harris, R. Laird

1980 The Theological Wordbook of The Old Testament. Vol. I.

Heavenor, E.S.P.

Chicago : Moody Press.

1980 Tafsiran Alkitab Masa Kini. II. Jakarta: BPK. Gunung Mulia.

Henry, Mathew

1960 Commentary On The Whole Bible, Grand Rapids: Zondervan Publishing House.

Keil, C.F. \& Delitzsch, F.

1978 Commentary On The Old Testament. Vol. IV. Grand

Smick, Elmer B. Rapids: Wm. B. Eerdman Publishing Co.

1988 The Expositor's Bible Commentary. Vol. IV. Grand Rapids: Zondervan Publishing House.

Wilson, William

N.d. Wilson's Old Testament Word Studies, MC Lean: Mac Donald Publishing Co. 